tives was also obtained for a control series of women drawn from the same doctors' practices as those in which the fatalities occurred.

A strong relation was found between the use of oral contraceptives and death from pulmonary embolism or cerebral thrombosis in the absence of predisposing conditions. The mortality from these two diseases attributable to the use of oral contraceptives by healthy women was estimated at 1.3 per 100,000 users aged $20-34$ and 3.4 per 100,000 users aged $35-44$ per annum.

The women who died from coronary thrombosis in the absence of predisposing conditions had been using oral contraceptives more frequently than would have been expected from the experience of the control group, but the difference did not quite attain statistical significance, and the existence of a definite association is regarded as not proved. If it is considered justifiable to include deaths from coronary thrombosis in the above estimates of attributable mortality, they may be recalculated as 2.2 and 4.5 per 100,000 users per annum for women aged 20-34 and 35-44 respectively, figures which agree closely with the estimate of risk given by the Medical Research Council (1967) in its preliminary report. It is probable, however, that all these estimates of risk are too low because information from independent sources indicates that our control data substantially overestimated the use of oral contraceptives by the general population in 1966.

No evidence was found that the risk of thromboembolism was associated with the use of any particular oral contraceptive formulation.

Only $15 \%$ of the deaths of women who were found to have been using oral contraceptives were reported independently to the Committee on Safety of Drugs.

We wish to express our thanks to Dr. S. Ruttle for his help with the assessment of the fatal cases and to the following doctors who carried out the field work for this study: E. Anderson, P. M. Austin M. P. Baillie, G. M. Barendt, M. L. Blair, B. H. Bryson, J. R Clyne, E. M. Cruickshank, M. Dales, E. N. Davey, J. U. Dods, E. C. Evans, M. E. Evans, M. M. Grant, E. S. Hallifax, M. C. Halstead, A. H. Holmes, G. A. Z. Holti, R. E. S. James, M. McAlley, R. A. Mayer-Jones, S. F. Marwood, I. C. A. Moyse, A. S. Pearson, K. M. Pearson, Z. C. Randall, B. Richardson, W. Sharrard, A. Simpson, G. G. Thyne, J. Tisdall, S. J. Toogood, S. D. M. Waters, M. M. M. Williams, and S. Yealland.

We would like to thank Sir Austin Bradford Hill, Dr. D. A Cahal, Dr. R. Doll, Sir Derrick Dunlop, Professor D. J. Finney, and Professor L. J. Witts for their advice and encouragement. Wc wish to record our appreciation of the help of the Registrar Generals of England and Wales and Northern Ireland, the Association of the British Pharmaceutical Industry, Intercontinental Medical Statistic Limited, the Family Planning Association, and the many physicians, coroners, and records officers who made this study possible.

\section{REFERENCES}

Bickerstaff, E. R., and Holmes, J. M. (1967). Brit. med. F., 1, 726.

Cahal, D. A. (1965). Brit. med. F., 2, 1180.

Food and Drug Administration (1963). Final Report on Enovid by the Ad Hoc Committee for the Evaluation of a Possible Etiologic Relaion with Thromboembolic Conditions. Food and Drug Administration, Department of Health, Education, and Welfare, Washington, U.S.A.

Food and Drug Administration (1966). Report on the Oral Contraceptives. Advisory Committee on Obstetrics and Gynecology. Washington, U.S.A.

Illis, L., Kocen, R. S., McDonald, W. I., and Mondkar, V. P. (1965). Brit. med. $7 ., 2,1164$.

Mantel, N., and Haenszel, W. (1959). 7. nat. Cancer Inst., 22, 719.

Medical Research Council (1967). Brit. med. 7., 2, 355.

Royal College of General Practitioners (1967). 7. roy. Coll. gen. Practit., $13,267$.

Vessey, M. P., and Doll, R. (1968). Brit. med. F., 2, 193.

Wynn, V., and Doar, J. W. H. (1966). Lancet, 2, 715.

Wynn, V., Doar, J. W. H., and Mills, G. L. (1966). Lancet, 2, 720

\title{
Investigation of Relation Between Use of Oral Contraceptives and Thromboembolic Disease
}

\author{
M. P. VESSEY,* M.B., B.S. ; RICHARD DOLL,* M.D., D.SC., F.R.C.P., F.R.S.
}

In May 1967 a subcommittee of the Medical Research Council reviewed the preliminary results of three inquiries into the risks of thromboembolic disease in women taking oral contraceptives. One study concerned episodes of thromboembolic disease seen in general practice, and the final results have been reported by the Royal College of General Practitioners (1967). Another concerned women who died of thromboembolic disease in England, Wales, and Northern Ireland in 1966 ; it was undertaken by the Committee on Safety of Drugs, the full results being reported elsewhere in this issue by Inman and Vessey (1968). The third, which was carried out by the Medical Research Council's Statistical Research Unit, concerned women admitted to hospital for deep vein thrombosis and pulmonary embolism. We now report the final results of this study, based on more than double the number of patients, and add some new data on women with cerebral or coronary thrombosis.

- Medical Research Council's Statistical Research Unit, University College Hospital Medical School, London W.C.I.

\section{Deep Vein Thrombosis and Pulmonary Embolism}

\section{Method}

Co-operation was sought and obtained from the medical staff of the 19 general hospitals of more than 300 beds situated in the catchment area of the North-West Metropolitan Regional Hospital Board, which maintained a sufficiently detailed nosological index. At each hospital the index was searched and the case notes were reviewed relating to all women who (1) had been admitted to hospital in 1964-6 ; (2) were aged 16 to 40 years inclusive; and (3) had been diagnosed as suffering from a condition coded Nos. 463-466 in the International Classification of Diseases (World Health Organization, 1957) ${ }^{1}$ - that is, from phlebitis, thrombophlebitis, thrombosis, or embolism in any vein except the cerebral, coronary, hepatic, and mesenteric veins; pulmonary embolism or infarction.

${ }^{1}$ Or the equivalent numbers at the four hospitals which used other codin systems. 
All women who satisfied these criteria were included unless they: (1) were single or widowed; (2) had an evident predisposing reason for developing the disease-that is, were suffering from some other relevant acute. or chronic disease or had within the previous three months been pregnant, undergone a surgical operation, or suffered trauma requiring hospital treatment ; (3) were pregnant, postmenopausal, or sterilized ; (4) had suffered only superficial thrombophlebitis; or (5) could not be interviewed because they had died during their stay in hospital.

If there was a doubt about the eligibility of a patient for inclusion, an abstract of the case history was prepared, omitting reference to contraceptive habits, and the decision was made independently by a colleague (Dr. Frank Speizer).

For each affected patient two control patients were selected who had been diagnosed as suffering from an acute medical or surgical condition or had been admitted to hospital for an elective operation (other than on varicose veins), and who matched the affected patient in regard to hospital, date of admission (within four months), age (within four years), parity (within groups $0,1-2$, or 3 or more deliveries), and absence of any of the attributes used to exclude patients from the affected series.

Permission to interview the patients was obtained from hospital consultants and general practitioners; the patients were then interviewed in their homes by a medical social worker experienced in research (Miss Keena Jones). At this interview inquiries were made about the patient's medical, obstetric, social, family, and contraceptive history.

Efforts were made to trace all the patients, but no attempt was made to contact those who had left the United Kingdom and Ireland. When control patients were found to have emigrated others were substituted for them. A few patients who could not be interviewed personally were asked to complete a postal questionary instead.

\section{Material}

Altogether 399 patients were identified who had been treated for venous thrombosis or pulmonary embolism. Of these, 338 were excluded for the reasons given in Table $\mathrm{I}$. The criteria for exclusion were applied in the order shown, so that if, for

TABLE I.-Reasons for Exclusion of Patients Diagnosed as Having Venous Thrombosis or Pulmonary Embolism

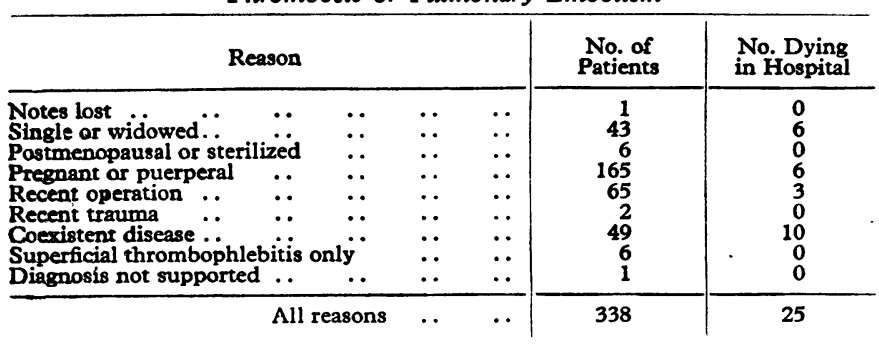

example, a patient was single or widowed, no further examination of the case notes was made. It is notable that only one set of notes required for review was untraced and only one patient was excluded because the discharge diagnosis was not supported.

Details of the 49 patients excluded because of coexistent disease are shown in Table II. Patients were excluded for this reason only if they suffered from a disease involving the cardiovascular system or blood (including diabetes mellitus), malignant disease, or a condition which required a period of bed rest during which the thromboembolic episode occurred.

The remaining 61 patients, who were regarded as having suffered from deep vein thrombosis or pulmonary embolism without any evident predisposing cause, formed the subject of the study. On average about one such patient had been admitted each year to each of the 19 hospitals, but the actual number identified at each hospital in all three years ranged from none to nine. Of these patients, 57 were interviewed and three answered our questions by post. One had emigrated to Australia and was net contacted.

\begin{tabular}{|c|c|c|c|}
\hline Disease Group & $\begin{array}{l}\text { Diseases included } \\
\text { (No. of Patients shown in Parentheses) }\end{array}$ & $\begin{array}{l}\text { Toeal } \\
\text { No. of } \\
\text { Paticuts } \\
\text { Beche- } \\
\text { ded }\end{array}$ & $\begin{array}{l}\text { Ne. of } \\
\text { Patient } \\
\text { Dying } \\
\text { in } \\
\text { Hompioul }\end{array}$ \\
\hline $\begin{array}{l}\text { Diseases involving } \\
\text { cardiovascular } \\
\text { system or blood }\end{array}$ & 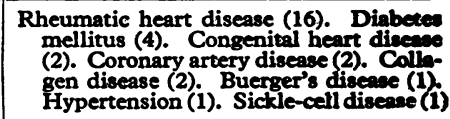 & 29 & 4 \\
\hline & $\begin{array}{l}\text { Cancer of stomach (2), brain (1), breast } \\
\text { (1), oesophagus (1), pancreas (1) } \\
\text { Self-poisoning (4). Chronic skin ulcen }\end{array}$ & 6 & 3 \\
\hline $\begin{array}{l}\text { Other defined dis- } \\
\text { eases (see text) }\end{array}$ & 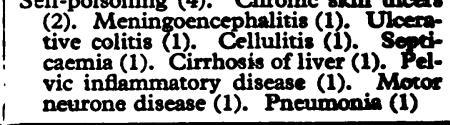 & 14 & 3 \\
\hline All diseases & .. & 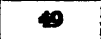 & 10 \\
\hline
\end{tabular}

One hundred and twenty-two patients were selected as controls. Five had emigrated and others were substituted for them. Of the new total, 111 were interviewed, 9 answered our questions by post, 1 was not interviewed because her husband refused permission, and 1 was untraced. We then had 58 complete "sets" of matched patients between whom comparisons could be made, including 58 affected patients and 116 controls.

The diagnoses of the control patients are shown in Table III : a wide range of diagnoses was covered and more than half the patients suffered from an acute condition that could not have been anticipated.

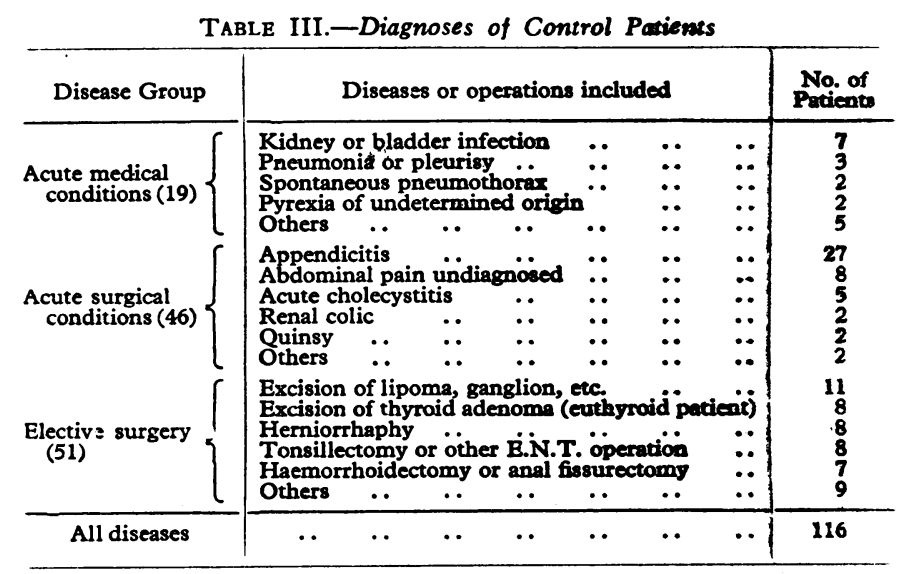

\section{Results}

Table IV shows the proportion of patients who bad been taking an oral contraceptive during the month before the start of the episode for which they were admitted to hospital or the month before admission in the case of patients undergoing elective surgery. ${ }^{2}$ This proportion was much higher in those admitted for deep vein thrombosis or pulmonary embolism (26 out of 58 , or $45 \%$ ) than in those admitted for other conditions ( 10 out of 116 , or $9 \%$ ) and the difference between the

"We have included under the general term "oral contraceptives" those oestrogen-progestogen mixtures normally prescribed for a gynaecological indication rather than for oral contraception. All patient were asked about the use of such preparations, and two affected patients were found to have been using Metrulen-M (a mixture of mestranol and ethynodia!, identical to Ovulen). 
proportions in the two groups is statistically highly significant $(\mathbf{P}<0.001)$.

TABLE IV.-Affected and Control Patients Classified by Use of Oral Contracoptives During Month Before Onset of Disease Episode (or Dwring Month Before Hospital Admission in Case of Patients Undergoins Elaction Surgery) (Percentages Shown in Parentheses)

\begin{tabular}{|c|c|c|c|c|c|c|}
\hline \multirow{3}{*}{\multicolumn{2}{|c|}{ Dianoetic Group }} & \multirow{2}{*}{\multicolumn{3}{|c|}{$\frac{\text { No. of Patients }}{\text { Oral contraceptives }}$}} & \multirow{3}{*}{\multicolumn{2}{|c|}{ All Women }} \\
\hline & & & & & & \\
\hline & & Used & \multicolumn{2}{|c|}{ Not used } & & \\
\hline 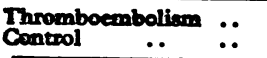 & $\ddot{0}$ & $\begin{array}{ll}26 & (45) \\
10 & (9)\end{array}$ & $\begin{array}{r}32 \\
106\end{array}$ & $\begin{array}{l}(55) \\
(91)\end{array}$ & $\begin{array}{r}58 \\
116\end{array}$ & $(100)$ \\
\hline \multicolumn{2}{|l|}{ Boch proups } & (21) & 138 & (79) & 174 & $(100)$ \\
\hline
\end{tabular}

$x^{2}=28.7, n=1, P<0.001$.

Note. The normal $x^{2}$ test is likely to overestimate the probability of obtaining uch extreme results by chance, as it fails to take account of the way in which the fected and contral patients were matched. A test suggested by Professor D. J. coared separately, gives: $t=5.3, n=57, P<0.001$.

Of the affected patients in the three incompletely matched "sets" one is known to have been taking oral contraceptives when she became ill, one is known not to have been, and no certain information is available for the third patient, who had cmigrated.

It is clear from the time relationships that the occurrence of the episode cannot have determined the use of this type of contraceptive; but it does not necessarily follow that the contraceptive was responsible for the disease. First we must consider whether any other difference between the groups could have led to the development of both features.

\section{Comparability of Groups}

The method of selecting the controls ensured that the patients in both groups were comparable with respect to age, marital status, and parity, and also to hospital and date of sdmission. Table $\mathrm{V}$ shows that they were comparable in respect of their country of origin and religion, the social class of their busband, and the interval between the birth of their last child and the onset of the current episode of disease. Differences were, however, recorded in the frequency of previous thromboembolic disease, the distribution of obesity, and the prevalence of smoking.

Altogether 26 patients reported previous attacks of superficial Ir deep vein thrombosis or pulmonary embolism-18 during pregnancy or the puerperium and 8 at other times when oral contraceptives were not being used. Table VI shows that the proportion of affected patients who reported previous attacks $36 \%$ ) was significantly higher than the proportion of control patients (4\%). Among the affected patients the proportion was

raBL V.-Comparability of Patients with Venous Thromboembolism

\begin{tabular}{|c|c|c|c|c|c|}
\hline \multirow{2}{*}{ Attribute } & \multicolumn{2}{|c|}{ No. of Patients } & \multirow{2}{*}{ Attribute } & \multicolumn{2}{|c|}{ No. of Patients } \\
\hline & $\begin{array}{l}\text { Thrombo- } \\
\text { enbolism }\end{array}$ & Control & & $\begin{array}{l}\text { Thrombo- } \\
\text { embolism }\end{array}$ & Control \\
\hline 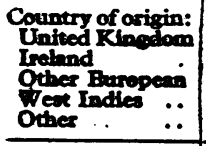 & $\begin{array}{r}41 \\
7 \\
3 \\
3 \\
4 \\
\end{array}$ & $\begin{array}{r}82 \\
11 \\
9 \\
6 \\
8 \\
\end{array}$ & $\begin{array}{l}\text { Religion: } \\
\text { Church of England } \\
\text { Nonconformist... } \\
\text { Roman Catholic } \\
\text { Other or none .. }\end{array}$ & $\begin{array}{r}35 \\
5 \\
13 \\
5\end{array}$ & $\begin{array}{r}70 \\
14 \\
27 \\
5\end{array}$ \\
\hline Total ... & 58 & 116 & Total & 58 & 116 \\
\hline 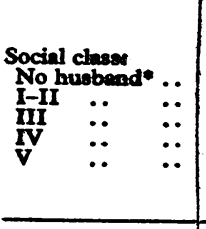 & $\begin{array}{r}5 \\
7 \\
34 \\
10 \\
2\end{array}$ & $\begin{array}{r}6 \\
19 \\
70 \\
18 \\
3\end{array}$ & 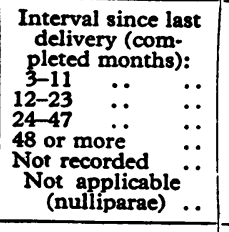 & $\begin{array}{r}7 \\
9 \\
14 \\
22 \\
0 \\
6 \\
\end{array}$ & $\begin{array}{r}12 \\
28 \\
23 \\
39 \\
2 \\
12 \\
\end{array}$ \\
\hline Total .. & 58 & 116 & Total & 58 & 116 \\
\hline
\end{tabular}

approximately the same irrespective of the subsequent use of oral contraceptives. This was unexpected because many doctors regard a history of thromboembolism as a contraindication to the use of this type of contraceptive.

TABLE VI.-History of Previous Venous Thrombosis or Pulmonar Embolism in Affected and Control Patients (Percentages Shown in Parentheses)

\begin{tabular}{|c|c|c|c|c|c|}
\hline \multirow[t]{2}{*}{ Diagnostic Group } & \multirow{2}{*}{$\begin{array}{l}\text { Oral } \\
\text { contracep- } \\
\text { tives }\end{array}$} & \multicolumn{2}{|c|}{$\begin{array}{l}\text { No. of patients with } \\
\text { history of previous venous } \\
\text { thromboembolic disease }\end{array}$} & \multirow{2}{*}{\multicolumn{2}{|c|}{ All Women }} \\
\hline & & Present & Absent & & \\
\hline \multirow{2}{*}{ Thromboembolism \{} & $\begin{array}{l}\text { Used } \\
\text { Not used... }\end{array}$ & $\begin{array}{r}9 \\
12 \quad(35)\end{array}$ & $\begin{array}{ll}17 & (65) \\
20 & (62)\end{array}$ & $\begin{array}{l}26 \\
32\end{array}$ & $\begin{array}{l}(100) \\
(100)\end{array}$ \\
\hline & Total .. & $21 \quad(36)$ & 37 (64) & 58 & $(100)$ \\
\hline \multirow[t]{2}{*}{ Control . } & $\begin{array}{l}\text { Used } \\
\text { Not used... }\end{array}$ & $\begin{array}{ll}2 & (20) \\
3 & (3)\end{array}$ & \begin{tabular}{rr|}
8 & $(80)$ \\
103 & $(97)$
\end{tabular} & $\begin{array}{r}10 \\
106\end{array}$ & $\begin{array}{l}(100) \\
(100)\end{array}$ \\
\hline & Total .. & (4) & 111 (96) & 116 & $(100)$ \\
\hline
\end{tabular}

Comparison between frequency of previous attacks (all affected and contro (ients): $\chi^{2}=28.5, \mathrm{n}=1, \mathrm{P}<0.00$

(affected and contro previous attacks): $x^{2}=27 \cdot 0, n=1, P<0.001$.

One hundred and forty-eight patients had never had a previous attack of thromboembolism, and in these women also the use of oral contraceptives was significantly more frequent in the affected group (17 out of 37 , or $46 \%$ ) than in the control group ( 8 out of 111 , or $7 \%$ ). In these women the prevalence of varicose veins-determined by the woman's history-was approximately the same in both the affected patients and the controls (19 and $24 \%$ respectively), and only 3 of the 17 affected women who used oral contraceptives were aware of ever having had varicose veins. These data therefore contradict Rivlin's (1967) suggestion that oral contraceptives produce phlebitis only when varicose veins are present.

Hospital records were too incomplete to be used as a source of information about physical measurements. The women were therefore asked about their height and weight at the time of the relevant hospital admission, and the stated weight was compared with the standard weight given by Billewicz, Kemsley, and Thomson (1962) for women of the same age and height. Table VII shows the mean difference between the stated and standard weights for the affected and control patients. The control women not using oral contraceptives were, on average, $3 \mathrm{lb}$. (1.4 kg) above the standard weight for their height and age, but with the use of oral contraceptives the difference increased to $7 \mathrm{lb}$. $(3.2 \mathrm{~kg}$.). Among the affected women who used oral contraceptives the difference was similar, but those women who were not using oral contraceptives weighed, on average, nearly $13 \mathrm{lb}$. $(5.9 \mathrm{~kg}$.) more than the standard. This large excess was due to the presence of 10 women ( $32 \%$ of the total) who weighed $28 \mathrm{lb}$. (12.7 kg.) or more above the standard. In each of the three other groups the proportion of such obese women was approximately $10 \%$.

Table VIII shows that the affected patients were, on average, heavier smokers than the control patients. The difference, however, is statistically not quite significant, and it will be noted that the proportion of women who used oral contraceptives was greater for the affected patients than for the controls in each smoking category.

TABLE VII.-Average Deviations of Stated Weights from Standard Weights (Number of Patients Shown in Parentheses)

\begin{tabular}{|c|c|c|c|c|c|}
\hline \multirow{3}{*}{\multicolumn{2}{|c|}{$\begin{array}{l}\text { Diagnostic } \\
\text { Group }\end{array}$}} & \multirow{2}{*}{\multicolumn{2}{|c|}{$\begin{array}{c}\text { Average deviation from } \\
\text { standard waight (lb.) } \\
\text { Oral contraceptives }\end{array}$}} & \multirow{3}{*}{\multicolumn{2}{|c|}{ All Women }} \\
\hline & & & & & \\
\hline & & Used & Not Used & & \\
\hline $\begin{array}{l}\text { Thromboembolism } \\
\text { Control } \quad . . \\
\end{array}$ & $\because$. & $\begin{array}{rr}+7.4 & (24) \\
+7.1 & (10) \\
\end{array}$ & $\begin{array}{r}+12.9(31) \\
+3.0(103) \\
\end{array}$ & $\begin{array}{r}+10.5 \\
+3.4 \\
\end{array}$ & (155)* \\
\hline Both groups & .. & $+7 \cdot 3$ & $+5.3 \quad(134)$ & +5.7 & $(168)$ \\
\hline
\end{tabular}

- Weight not known for 3 patients in each diagnostic group. 
The data summarized in Tables VI, VII and VIII provide no evidence that previous attacks of disease, obesity, or smoking could have accounted for the association between the use of oral contraceptives and the development of thromboembolism. They accord with other experience suggesting that

TABLE VIII.-Prevalence of Cigarette Smoking in Affected and Control Patients (Number of Patients in Each Class is Given with Percentages in Parentheses

\begin{tabular}{|c|c|c|c|c|c|c|}
\hline \multirow{2}{*}{$\begin{array}{l}\text { Diagnostic } \\
\text { Group }\end{array}$} & \multirow{2}{*}{$\begin{array}{c}\text { Oral } \\
\text { Contra- } \\
\text { ceptives }\end{array}$} & \multicolumn{3}{|c|}{$\begin{array}{c}\text { No. of Cigarettes Smoked } \\
\text { at onset of Episode } \\
\end{array}$} & \multirow{2}{*}{$\begin{array}{c}\text { Total No. } \\
\text { of } \\
\text { Patients }\end{array}$} & \multirow{2}{*}{$\begin{array}{c}\text { Mean No. of } \\
\text { Cigarettes } \\
\text { Smoked }\end{array}$} \\
\hline & & 0 & $1-14$ & $15+$ & & \\
\hline \multirow{2}{*}{$\begin{array}{c}\text { Thrombo- } \\
\text { cmbolism }\end{array}$} & $\begin{array}{l}\text { Used } \\
\text { Not used }\end{array}$ & $\begin{array}{r}8(31) \\
11(34)\end{array}$ & $14(15)$ & $\begin{aligned} 14(54) \\
7(22)\end{aligned}$ & $\begin{array}{l}26(100) \\
32(100)\end{array}$ & $\begin{array}{r}15 \\
7\end{array}$ \\
\hline & Total & $19(33)$ & $18(31)$ & $21(36)$ & $58(100)$ & 11 \\
\hline \multirow[t]{2}{*}{ Control } & $\begin{array}{l}\text { Used } \\
\text { Not used }\end{array}$ & $\begin{array}{r}3(30) \\
49(46) \\
\end{array}$ & $\begin{array}{r}5(50) \\
35(33) \\
\end{array}$ & $\begin{array}{r}22(20) \\
22(21) \\
\end{array}$ & $\begin{array}{l}10(100) \\
106(100) \\
\end{array}$ & 7 \\
\hline & Total & $52(45)$ & $40(34)$ & $24(21)$ & $116(100)$ & 7 \\
\hline
\end{tabular}

Comparison between affected patients and controls, $x^{2}=5 \cdot 13, n=2,0.10>P$ $\rightarrow 0.05$.

the risk of thromboembolism is increased by previous attacks and by obesity (Coon and Coller, 1959b ; Fleming and Bailey, 1966) and that the use of oral contraceptives tends to increase weight (World Health Organization, 1966).

\section{Bias in Diagnosis}

An alternative explanation of the results is that a history of the use of oral contraceptives led to the recognition of thromboembolic disease which would otherwise have been missed. It is easy to overlook the diagnosis of both deep vein thrombosis and pulmonary embolism (Coon and Coller, 1959a; Medd and McBrien, 1962 ; Hamilton and Thompson, 1963 ; Richards, 1966), and the reports of thrombosis in women who used oral contraceptives, which began to appear in British medical journals in 1961, will have alerted doctors to the possibility of its occurrence.

If this were the explanation, the strongest association should be found in those patients for whom the diagnosis was least evident, as this group would contain patients whose condition was diagnosed only because they were known to have been using oral contraceptives. We have therefore sought to test this hypothesis by classifying the affected patients according to the confidence placed in the diagnosis. For this purpose we made detailed summaries of the records of all 61 affected patients, omitting reference to their contraceptive practice, and submitted these summaries to a colleague (Dr. Frank Speizer), who classified the diagnoses as "possible," "probable," or " certain." No patient was classified as certainly having deep vein thrombosis alone, because none had been submitted to phlebography or vascular surgery (Hæger, Nilsson, and Robertson, 1967). No patient was diagnosed as possibly having both deep vein thrombosis and pulmonary embolism, as the combination of signs in the leg and chest was regarded

TABLr IX.-Classification of Certainty of Diagnosis of Venous Thromboembolic Disease by Oral Contraceptive Use of Affected Patients (the Number of Patients in Each Class is Given)

\begin{tabular}{|c|c|c|c|c|c|c|c|c|}
\hline \multirow{3}{*}{$\begin{array}{l}\text { Certainty } \\
\text { of } \\
\text { Diremoais }\end{array}$} & \multicolumn{2}{|c|}{$\begin{array}{l}\text { Deep Vein } \\
\text { Thrombosis }\end{array}$} & \multicolumn{2}{|c|}{$\begin{array}{l}\text { Pulmonary } \\
\text { Embolism }\end{array}$} & \multicolumn{2}{|c|}{$\begin{array}{l}\text { Deep Vein } \\
\text { Thrombosis } \\
\text { and Pulmonary } \\
\text { Embolism }\end{array}$} & \multicolumn{2}{|c|}{$\begin{array}{c}\text { All types of } \\
\text { Venous } \\
\text { Thrombo- } \\
\text { Embolism }\end{array}$} \\
\hline & \multicolumn{8}{|c|}{ Oral Contraceptives } \\
\hline & Used & $\begin{array}{l}\text { Not } \\
\text { used }\end{array}$ & Used & $\begin{array}{c}\text { Not } \\
\text { used }\end{array}$ & Used & $\begin{array}{l}\text { Not } \\
\text { used }\end{array}$ & Used & $\begin{array}{l}\text { Not } \\
\text { used }\end{array}$ \\
\hline $\begin{array}{l}\begin{array}{l}\text { Pososible } \\
\text { Probeble }\end{array} \\
\text { Certain }\end{array}$ & $\underline{2}$ & $\begin{array}{r}7 \\
15 \\
-\end{array}$ & $\begin{array}{l}1 \\
2 \\
3 \\
\end{array}$ & $\begin{array}{l}1 \\
3 \\
0\end{array}$ & $\overline{2}$ & $\begin{array}{l}5 \\
3 \\
\end{array}$ & $\begin{array}{r}3 \\
15 \\
9 \\
\end{array}$ & $\begin{array}{r}8 \\
23 \\
3\end{array}$ \\
\hline Total & 13 & 22 & 6 & 4 & 8 & 8 & 27 & 34 \\
\hline
\end{tabular}

as sufficiently strong evidence to justify classing the diagnosis as at least "probable."

Table IX shows that within each disease category the use of oral contraceptives was no greater, and was indeed less, when the diagnosis was less certain, and that the proportion of affected patients who had used oral contraceptives was higher among those who suffered from the serious condition of pulmonary embolism than among those who suffered deep vein thrombosis alone. It seems improbable, therefore, that the observed association is due to a greater tendency to diagnose thromboembolic disease in women who use oral contraceptives.

\section{Distribution of Affected Patients by Calendar Year}

Table $\mathrm{X}$ shows the number of affected women admitted to hospital each year. No trend with time is evident. The numbers each year are small and the changes, though not providing much positive evidence in support, are statistically compatible with the hypothesis that the incidence of thromboembolism is static in women not using oral contraceptives and is rising in step with the number at risk in women who are.

TABLE X.-Number of Affected Patients Identified Each Year by Oral Contraceptive Use: An Estimate of Contraceptives Supplied in Aiso Given

\begin{tabular}{|c|c|c|c|c|c|c|c|}
\hline \multicolumn{4}{|c|}{ Oral Contraceptives } & \multirow{2}{*}{$\begin{array}{c}1964 \\
5 \\
9\end{array}$} & \multirow{2}{*}{$\begin{array}{c}1965 \\
11 \\
16\end{array}$} & \multirow{2}{*}{$\frac{1966}{11}$} & \multirow{2}{*}{$\begin{array}{c}\text { Total } \\
27 \\
34\end{array}$} \\
\hline $\begin{array}{l}\text { Used } \\
\text { Not used }\end{array}$ & $\because$. & 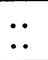 &.. & & & & \\
\hline Total & .. & .. &.. & 14 & 27 & 20 & 61 \\
\hline \multicolumn{4}{|c|}{$\begin{array}{l}\text { Estimate of oral contraceptives } \\
\text { supplied in England and Wales } \\
\text { (woman-years) }\end{array}$} & 250,000 & 400,000 & 600,000 & $1,250,000$ \\
\hline
\end{tabular}

* Based on information provided by Intercontinental Medical Statistics, Ltc (personal communication, 1967) and the Family Planning Association (Hill, persona communication, 1967).

It should be noted, however, that the incidence of thromboembolic disease may have been increasing before oral contraceptives were widely introduced (Morrell, Truelove, and Barr, 1963 ; Loehry, 1966) and the risk of thromboembolic disease may vary with the length of time oral contraceptives have been used and with the characteristics of the women who take them. We have evidence from one Family Planning Association clinic to show that women who took oral contraceptives in 1964 were, on average, older and more parous than women who took them in 1966, and these and other similar factors may affect the temporal trend.

\section{Type of Oral Contraceptive Used and Duration of Use}

The contraceptive preparations last in use before the onset of the relevant episode were known for 23 of the affected patients and for eight of the controls. These data were compared with expected distributions calculated on the basis of known supply figures (provided by Intercontinental Medical Statistics Ltd., personal communication, 1967). No indication was obtained that any one contraceptive formulation is more likely to be responsible for thromboembolic disease than the others, though only a marked effect would have been detectable with so few data. None of the affected women had been using sequential preparations; but this was to be expected as only about $2 \%$ of the oral contraceptives consumed during 1964-6 were of this sort.

Comparison of the duration of use of oral contraceptives was also handicapped by the small amount. of data. We may note, however, that $42 \%$ of the women who developed thromboembolic disease (11 out of 26 ) had been using oral contracep- 
tives for less than six months, and the corresponding proportion for the control patients was almost identical (4 out of 10).

\section{Family History}

All affected and control patients were questioned about the illnesses and causes of death of their parents and sibs. No significant differences were found between the numbers of relatives who had died from a variety of causes. There were, however, small differences in the reported frequency of morbidity from phlebitis among both mothers and sisters. Thus nine mothers and seven sisters of the affected women and nine mothers and two sisters of twice as many control women were reported to have suffered from non-fatal phlebitis. These differences may indicate family predilection for venous thromboembolism or they may be the result of preferential recall by the affected subjects. There was no suggestion that a positive family history might be more common among affected women who used oral contraceptives than among affected women who did not.

\section{Estimate of Incidence}

Data provided by the North-West Metropolitan Regional Hospital Board indicates that the hospitals participating in the study include approximately $60 \%$ of the Board's female acute general medical and surgical beds. All but one of the affected patients resided within the Board's catchment area at the time of admission to hospital, so that we can reasonably relate our findings to the population of that area.

The total number of woman-years at risk can be estimated by reducing the size of the total female population aged 16-40 years for the Board's area in 1965 (Registrar General, 1967) by appropriate factors to allow for the proportion of single, widowed, pregnant, and puerperal women, and then multiplying the result by three. No adjustment can, however, be made for the other factors taken into account in this study, such as the number of women with relevant chronic diseases or in the postoperative or postmenopausal state; but the number is unlikely to be large (not more, we would think, than $10 \%$ of the population). An estimate of the years at risk for women who took oral contraceptives can be made from supply figures for the country as a whole, on the assumption that women resident in the Board's area were representative of the whole population with respect to their use of oral contraceptives; and an estimate of the number of affected patients who did and who did not use oral contraceptives can be obtained by multiplying the observed numbers by 1.67 , on the assumption that the study covered $60 \%$ of the relevant hospital beds and that the one affected patient who was not resident in the area counterbalanced one affected resident who was treated elsewhere.

On this basis the annual attack rate of venous thromboembolic disease, without evident cause but of sufficient severity to require hospital admission, is about 5 per 100,000 (or 1 in 20,000 ) women who do not use oral contraceptives, and is about 10 times higher $(47$ per 100,000 , or 1 in 2,000$)$ in women of similar marital status who do. If the calculations are limited to women without previous venous thromboembolic disease the annual attack rate is reduced to about 1 in every 3,000 women who use oral contraceptives, but the relative risk is not materially altered. The two patients taking Metrulen-M have been omitted from these calculations as the use of this drug is not known for the estimated population at risk.

Relative risks can also be calculated directly from the hospital data given in Table IV. From these data the risk among women who use oral contraceptives is calculated to be about nine times that among women who do not (26/32 divided by 10/106). These two values for the relative risk, which use different sources of material for estimating the use of oral contraceptives in the general population, are in close agreement.

\section{Cerebral Thrombosis}

Women who were treated in hospital for cerebral thrombosis should have been recorded in the hospital diagnostic index under International Classification of Diseases rubric 332. This diagnosis, however, is difficult to establish accurately and some cases could be classified under other heads. All case notes were therefore examined relating to diagnoses coded under other rubrics for cerebrovascular disease-that is, numbers 331 to 334 -for the period 1964-6. A preliminary check showed that patients coded under rubric 330 (subarachnoid haemorrhage) almost always had blood-stained cerebrospinal fluid, and this rubric was omitted. At three hospitals the diagnostic indexes provided incomplete information about the sex and age of the patients. It was impracticable to review all the notes coded 331 to 334 at these hospitals and our results relate only to patients treated at the other 16 .

Firstly, all notes were excluded relating to women who were single or widowed, postmenopausal, sterilized, pregnant, or puerperal, or had a predisposing condition adequate to account for the development of a cerebrovascular disturbance. Secondly, notes were excluded which related to episodes where there was proof that the diagnosis was one of haemorrhage or which were obviously not due to cerebral thrombosis. Abstracts of the remaining 16 sets of notes were then prepared and were reviewed by a neurologist (Dr. Gerald Stern) without knowledge of the patients' contraceptive practice. Nine patients were accepted as having had a cerebral thrombosis, but the diagnosis was regarded as certain (angiographic evidence of arterial occlusion at a site which could be related to the focal signs) in only two.

The nine patients were interviewed in their homes (five) or completed postal questionaries (four) in the same way as the patients suffering from venous thrombosis or pulmonary embolism. Five (including one in whom the diagnosis was certain) had been using oral contraceptives during the month before they became ill and for periods ranging from one week to four years previously.

For comparison we have used the control patients selected to match the women with venous thromboembolic disease. Of these, 10 out of 116 used oral contraceptives (see Table IV), so that the crude number expected among the women with "cerebral thrombosis" would have been less than one (0.8). If account is taken of the age, parity, and year of admission of the women with "cerebral thrombosis" the expected number (1.0) is hardly altered. Even with these few patients the difference between the observed and the expected numbers of women using oral contraceptives is statistically significant $(\mathrm{P}<0.01)$.

\section{Coronary Thrombosis}

It was again impracticable to review all the notes coded under International Classification of Disease rubric 420 (arteriosclerotic heart disease, including coronary disease) at three hospitals, because the diagnostic index was incomplete and our results relate only to patients treated at 16 hospitals during the period 1964-6.

All notes were excluded relating to women who were single or widowed, postmenopausal, sterilized, pregnant, or puerperal, or had a predisposing condition; the remainder were classified into three diagnostic groups-angina pectoris only, possible coronary thrombosis (only ST or T changes in the electrocardiogram, but showing progression; serum enzymes either not done or offering no support to the diagnosis), and certain coronary thrombosis (pathological $Q$ waves in the electrocardiogram or only ST or T changes accompanied by supporting serum enzyme changes). None of the notes relating to patients in these categories made any mention of oral contraceptives; there was therefore no risk of bias, and the classification was made without reference to others. 
Sixteen women were accepted as having had coronary thrombosis without predisposing cause. Three had died and were excluded from the study because they could not be interviewed ; of the remainder, the diagnosis was regarded as certain in four. All 13 patients were either interviewed (12) or had completed a postal questionary (1), and none had taken oral contraceptives during the month before the onset of their disease. The number expected to have done so, from the experience of the control subjects selected to match the patients with venous thromboembolic disease, was $0.7 .^{3}$

\section{Discussion}

\section{Pulmonary Embolism and Deep Vein Thrombosis}

Retrospective studies of hospital patients are always open to bias, and the present study is no exception. Both the affected and the control patients were selected from larger groups by procedures that were certainly not random, and information about the use of oral contraceptives was obtained by inquiry of the patient and so was dependent on the accuracy of her memory. The evidence, however, suggests that these sources of bias have not materially affected the results.

Firstly, women were selected for inclusion only for objective reasons, and any subsequent decision to exclude them for subjective reasons-for example, the presence of doubtfully significant predisposing disease-was taken in ignorance of their contraceptive practice. Secondly, the proportion of women with deep vein thrombosis or pulmonary embolism who used oral contraceptives was greater when the diagnosis was firmly established than when the diagnosis was less certainand the contrary would be expected if diagnosis and referral to hospital were biased by knowledge of the women's contraceptive practice. Thirdly, the proportion of control women who said they were using oral contraceptives (9\%) was close to the proportion of married women estimated to use them: (1) from knowledge of available supplies (approximately $11 \%$ at ages 15 to 44 years in $1966^{4}$ ); and (2) from the experience of women on general practice lists ( $7 \%$ at ages 15 to 49 years in $\left.1965-66^{4}\right)$. Fourthly, the proportion of women treated for pulmonary embolism who said they were using oral contraceptives $(54 \%)$ is close to that recorded among women aged 20 to 44 years who died of pulmonary embolism in England, Wales, and Northern Ireland in 1966 (62\%, Inman and Vessey, 1968). We conclude, therefore, that the method of investigation has not materially biased the results and that the association between the use of oral contraceptives and the development of deep vein thrombosis or pulmonary embolism is real.

Two considerations suggest that the association reflects cause and effect. Firstly, we have been unable to find any evidence of a third factor which could account for the association by being related to both. Many factors which cause the disease or influence the use of contraceptives were excluded by the design of the study. Two-previous attacks of thromboembolism and obesity-were not excluded; both were found more commonly in affected patients, but neither was particularly associated with the use of oral contraceptives. Others were either unrelated to the disease or the relation was so weak that it could have had no material effect on the results. Secondly, there is evidence that oestrogens can cause thromboembolism in other circumstances (Daniel, Campbell, and Turnbull, 1967 ; Oliver, 1967 ; Bailar, 1967 ; Schrogie and Solomon, 1967).

Further evidence should eventually be obtained from examining trends in the incidence of the condition and its geographical distribution, particularly as the use of oral contraceptives has become more common than it was in 1966.

\footnotetext{
3 This number is less than that expected among nine patients with " cerebral thrambosis" because those with coronary thrombosis were, on average, older.

- Medical Research Council (1967).
}

The evidence, however, will not be easy to interpret, as the use of oral contraceptives is only one of many potential causes of thrombosis, and changes in the prevalence of the other factors may mask its effect.

If, as we now conclude, the use of oral contraceptives is a cause of venous thrombembolism, three questions arise. How big is the risk? Is it concentrated on a particular section of the population? And is it attributable to any one component ?

The results of our study are quantitatively similar to those obtained by the Royal College of General Practitioners (1967) and the Committee on Safety of Drugs (Inman and Vessey, 1968).

In the first of these studies the data relate mainly to superficial phlebitis, and it may be noted that the total morbidity from all types of thromboembolic disease was approximately 2 per 1,000 women per year and that the risk of venous thrombosis or pulmonary embolism in women who were taking oral contraceptives was increased approximately threefold. Only six women aged 15 to 39 years, however, were recorded as having a deep vein thrombosis or pulmonary embolism when neither pregnant nor puerperal (Crombie, personal communication, 1967); three used oral contraceptives and three did not, and two in each category were admitted to hospital. The resultant annual hospital admission rates (approximately 60 per 100,000 women who used oral contraceptives and 5 per 100,000 women who did not) are subject to large standerd errors, but are none the less similar to those calculated in the present study (47 and 5 per 100,000 respectively).

In the second study (Inman and Vessey, 1968) the data relate only to deaths and, in the case of pulmonary embolism, women who had suffered a previous thromboembolic episode were classified with women who had other predisposing conditions. Again, however, it may be noted that the relative risk among women who used oral contraceptives was increased about eight times, whereas in our study the relative risk of pulmonary embolism was increased approximately 12 times.

In any disease which is as rare as "idiopathic" deep vein thrombosis or pulmonary embolism it is always possible that the condition reflects an idiosyncratic reaction due to the patient's genetic constitution. Our data do not rule out this possibility, but neither do they provide any strong support for it. In particular there is no suggestion, either in this study or in that of the Committee on Safety of Drugs, that venous thromboembolism tends to occur shortly after beginning the use of oral contraceptives-as might be expected if the reaction was idiosyncratic.

The data are also too few to give any clear answer to the question of the relative effect of the different combinations of oestrogen and progestogen, but neither study provides any indication that there is likely to be much difference between. them.

\section{Cerebral and Coronary Thrombosis}

Our data contribute little new information relating to the occurrence of cerebral and coronary thrombosis. Only nine previously healthy women who were married and aged 40 years or under were treated for "cerebral thrombosis" and 16 (including three who died) from coronary thrombosis in 16 large hospitals in a three-year period. The diagnosis of cerebral: thrombosis is difficult to establish with certainty, and it is possible that the majority of patients in our small series suffered from some other intracranial condition. It is notable, however, that five of the nine patients had been using oral contraceptives when their disease began. This finding in itself implies little, but taken in conjunction with the similar findings of the Committee on Safety of Drugs (Inman and Vessey, 1968), of Bickerstaff and Holmes (1967), and of Illis et al. (1965), it justifies the conclusion that oral contraceptives can be a cause: 


\section{April 1968 Oral Contraceptives and Thr}

of episodes of cerebrovascular insufficiency. Only Jennett and Cross (1967), who studied 26 non-pregnant women suffering from "ischaemia in the carotid territory" during 1961-5, failed to find any evidence of an association.

Most of the nine patients in the present study suffered a mild illness followed by a good recovery. At the time of interview several of the patients complained of minor residual disabilities, but only one was still severely incapacitated by a slowly recovering left hemiplegia. She had suffered bilateral internal carotid artery thrombosis in September 1966, demonstrated by angiography, and had previously taken an oral contraceptive for several months.

Despite the fact that changes have been demonstrated in carbohydrate metabolism and the pattern of serum lipids in women taking oral contraceptives, which might be regarded as conducive to coronary thrombosis (Wynn and Doar, 1966; Wynn, Doar, and Mills, 1966), epidemiological studies have as yet provided very little confirmatory evidence. A few case histories have been reported-for example, Hartveit (1965)and a number of other studies have shown an excess mortality from coronary thrombosis in men treated with oestrogens for various reasons (see Schrogie and Solomon, 1967). The study of the Committee on Safety of Drugs (Inman and Vessey, 1968) is compatible with some increased risk under 35 years of age, but the 13 patients with non-fatal coronary thrombosis in our study (only five of whom were under 35 years of age) offer no further support. We conclude that the existence of a risk of coronary thrombosis is not proved. If, as our data suggest, women who use oral contraceptives are somewhat heavier smokers than average, this factor will need to be taken into account in interpreting future findings (Dörken, 1967).

\section{Summary and Conclusions}

Married women aged 16 to 40 years discharged during 196466 from 19 large general hospitals in the North-West Metropolitan Regional Hospital Board area with a diagnosis of deep vein thrombosis or pulmonary embolism without evident predisposing cause were identified by means of the hospital diagnostic indexes. They were subsequently interviewed in their homes, when inquiries were made about their past medical, obstetric, social, family, and contraceptive histories.

For comparison, married control patients admitted to the same hospitals with acute surgical or medical conditions, or for elective surgery, and matched with the affected pstients for age, parity, date of admission, and absence of any predisposing cause of thromboembolic disease, were also identified and similarly interviewed.

Of 58 affected patients $26(45 \%)$ had been using oral contraceptives during the month preceding the onset of their illness while only 10 of the corresponding 116 controls (9\%) had been doing so.

From these data it is calculated that the risk of hospital admission for venous thromboembolism is about nine times greater in women who use oral contraceptives than in those who do not. If national supply data are used for estimating the frequency of use of oral contraceptives in the general population it is calculated that about 1 in every 2,000 women using oral contraceptives are admitted to hospital each year with "idiopathic" venous thromboembolism in comparison with about 1 in every 20,000 women not using them.

These results are not thought to have been produced by bias or by any common factor responsible both for the use of oral contraceptives and the production of thromboembolism, and it is concluded that oral contraceptives are a cause of the disease.

At 16 hospitals women suffering from coronary or cerebral thrombosis were also studied. Five of nine patients who survived an attack of "cerebral thrombosis" had been using oral contraceptives during the month preceding their illness. Taken in conjunction with other similar findings, it is justifiable to conclude that oral contraceptives can also be a cause of cerebrovascular insufficiency.

Of the 13 women who survived an attack of coronary thrombosis without evident predisposing cause none had been using oral contraceptives.

We should like to express our thanks to the many people who have helped with this work, and especially to Miss Keena Jones, who traced and interviewed the patients ; to Miss Rosemary Emerson, who gave technical assistance throughout; to Dr. S. Mackenzie, who provided information about hospitals in the North-West Metropolitan Regional Hospital Board ; to Dr. F. E. Speizer and Dr. G. M. Stern, who assessed many of the case histories; to the consultants and general practitioners who allowed us to study patients under their care; to the hospital records officers and coding clerks who gave willing assistance in many different ways; and to the patients themselves, who gave up their time to answer our questions.

\section{REFERENCES}

Bailar, J. C. (1967). Lancet, 2, 560.

Bickerstaff, E. R., and Holmes, J. M. (1967). Brit. med. f., 1, 726.

Billewicz, W. Z., Kemsley, W. F., and Thomson, A. M. (1962). Brit. f. prev. soc. Med., 16, 183

Coon, W. W., and Coller, F. A. (1959a). Surg. Gynec. Obstet., 109, 259.

Coon, W. W., and Coller, F. A. (1959b). Surg. Gynec. Obstet., 109, 487.

Daniel, D. G., Campbell, H., and Turnbull, A. C. (1967). Lancet, 2, 287.

Dörken, H. (1967). Münch. med. Wschr., 109, 187.

Fleming, H. A., and Bailey, S. M. (1966). Brit. med. F., 1, 1322.

Hæger, K., Nilsson, I. M., and Robertson, B. (1967). Brit. med. 7., 3. 493.

Hamilton, M., and Thompson, E. N. (1963). Postgrad. med. F., 39, 348 Hartveit, F. (1965). Brit. med. F., 1, 60.

Illis, L., Kocen, R. S., McDonald, W. I., and Mondkar, V. P. (1965) Brit. med. f., 2, 1164 .

Inman, W. H. W., and Vessey, M. P. (1968). Brit. med. f., 2, 199.

Jennett, W. B., and Cross, J. N. (1967). Lancet, 1, 1019.

Loehry, C. A. (1966). Brit. med. 7., 1, 1327.

Medd, W. E., and McBrien, D. J. (1962). Lancet, 1, 944.

Medical Research Council (1967). Brit. med. F., 2, 355. Morrell, M. T., Truelove, S. C., and Barr, A. (1963). Brit. med. J., 2.
2.

Oliver, M. F. (1967). Lancet, 2, 510.

Registrar Gener.l of England and Wales (1967). Statistical Review of England and Wales for the Year 1965, Part II. H.M.S.O., London. Richards, R. L. (1966). Brit. med. f., 2, 217.

Rivlin, S. (1967). Brit. med. F., 3, 864.

Royal College of General Practitioners (1967). f. roy. Coll. gen. Practis. $13,267$.

Schrogie, J. J., and Solomon, H. M. (1967). F. chron. Dis., 20, 675.

World Health Organization (1957). Manual of the International Statistical Classification of Diseases, Injuries, and Causes of Death. Geneva. World Health Organization (1966). Wld Hlth Org. techn. Rep. Ser.,
No. 326.

Wynn, V., and Doar, J. W. H. (1966). Lancet, 2, 715.

Wynn, V., Doar, J. W. H., and Mills, G. L. (1966). Lancet, 2, 720. 